\title{
CCL-1 in the spinal cord contributes to neuropathic pain induced by nerve injury
}

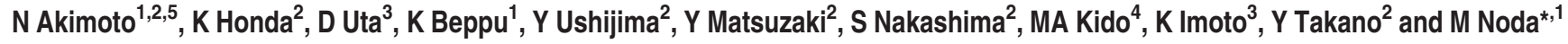

Cytokines such as interleukins are known to be involved in the development of neuropathic pain through activation of neuroglia. However, the role of chemokine (C-C motif) ligand 1 (CCL-1), a well-characterized chemokine secreted by activated T cells, in the nociceptive transmission remains unclear. We found that CCL-1 was upregulated in the spinal dorsal horn after partial sciatic nerve ligation. Therefore, we examined actions of recombinant CCL-1 on behavioural pain score, synaptic transmission, glial cell function and cytokine production in the spinal dorsal horn. Here we show that CCL-1 is one of the key mediators involved in the development of neuropathic pain. Expression of CCL-1 mRNA was mainly detected in the ipsilateral dorsal root ganglion, and the expression of specific CCL-1 receptor CCR-8 was upregulated in the superficial dorsal horn. Increased expression of CCR-8 was observed not only in neurons but also in microglia and astrocytes in the ipsilateral side. Recombinant CCL-1 injected intrathecally (i.t.) to naive mice induced allodynia, which was prevented by the supplemental addition of $N$-methyl-D-aspartate (NMDA) receptor antagonist, MK-801. Patch-clamp recordings from spinal cord slices revealed that application of CCL-1 transiently enhanced excitatory synaptic transmission in the substantia gelatinosa (lamina II). In the long term, i.t. injection of CCL-1 induced phosphorylation of NMDA receptor subunit, NR1 and NR2B, in the spinal cord. Injection of CCL-1 also upregulated mRNA level of glial cell markers and proinflammatory cytokines (IL-1 $\beta$, TNF- $\alpha$ and IL-6). The tactile allodynia induced by nerve ligation was attenuated by prophylactic and chronic administration of neutralizing antibody against CCL-1 and by knocking down of CCR-8. Our results indicate that CCL-1 is one of the key molecules in pathogenesis, and CCL-1/CCR-8 signaling system can be a potential target for drug development in the treatment for neuropathic pain.

Cell Death and Disease (2013) 4, e679; doi:10.1038/cddis.2013.198; published online 20 June 2013

Subject Category: Neuroscience

Neuropathic pain (also classified as chronic or malignant pain) is associated with nerve injury of multiple aetiology that includes acute trauma, diabetes, cancer, infection and autoimmune pathology. ${ }^{1}$ Pathogenesis of neuropathic pain reflects complex remodelling of the spinal cord, with primary role attributed to change of synaptic transmission and activation of neuroglial cells, astrocytes and microglia. ${ }^{2-4}$

Glutamate, the major excitatory neurotransmitter in the brain and spinal cord, exerts its postsynaptic effects via a diverse set of ionotropic and metabotropic membrane receptors. The glutamate ionotropic $N$-methyl-D-aspartate receptors (NMDARs), specifically those localized in the dorsal horn of the spinal cord, are critically involved in nociceptive transmission and synaptic plasticity and have long been considered a target for the treatment of neuropathic pain. ${ }^{5,6}$ The native neuronal NMDAR is a tetramer that consists of two NR1 and two NR2 subunits. ${ }^{7}$ Phosphorylation of multiple sites in the cytoplasmic $C$ termini of the NR1 and NR2 subunits is known to modulate NMDAR activity and affect synaptic transmission. ${ }^{8-10}$

\footnotetext{
${ }^{1}$ Laboratory of Pathophysiology, Graduate School of Pharmaceutical Sciences, Kyushu University, 3-1-1 Maidashi, Higashi-ku, Fukuoka 812-8582, Japan; ${ }^{2}$ Department of Physiology and Pharmacology, Faculty of Pharmaceutical Sciences, Fukuoka University, 8-19-1 Nanakuma, Jo, Fukuoka 814-0180, Japan; ${ }^{3}$ Department of Information Physiology, Division of Neural Signaling, National Institute for Physiological Sciences, 5-1 Higashiyama, Myodaiji, Okazaki 444-8787, Japan and ${ }^{4}$ Department of Molecular Cell Biology and Oral Anatomy, Graduate School of Dental Science, Kyushu University, 3-1-1 Maidashi, Higashi-ku, Fukuoka 812-8582, Japan *Corresponding author: M Noda, Laboratory of Pathophysiology, Graduate School of Pharmaceutical Sciences, Kyushu University, 3-1-1 Maidashi, Higashi-ku, Fukuoka 812-8582, Japan. Tel: +81 92642 6574; Fax: +81 92642 6574; E-mail: noda@phar.kyushu-u.ac.jp

${ }^{5}$ Research Fellow of the Japan Society for the Promotion of Science

Keywords: CCL-1; neuropathic pain; glutamate; spinal cord; NMDA receptor

Abbreviations: AMPA, alpha-amino-3-hydroxy-5-methyl-4-isoxazolepropionic acid; AMV, avian myeloblastosis virus; ANOVA, analysis of variance; ATP, adenosine triphospjate; BDNF, brain-derived neurotrophic factor; CCL-1, chemokine (C-C motif) ligand 1; CCL-2, chemokine (C-C motif) ligand 2; CCL-21, chemokine (C-C motif) ligand 21; CCR-8, chemokine (C-C motif) receptor 8; CX3CL-1, chemokine (CX3C motif) ligand 1; DAPI, 4', 6'-diamidino-2-phenylindole, dihydrochloride; DMEM, Dulbecco's modified eagle medium; DRG, dorsal root ganglion; EGTA, ethylene glycol tetraacetic acid; FBS, fetal bovine serum; GABA, $\gamma$-amino butyric acid; GFAP, glial fibrillary acid protein; HEPES, 4-(2-hydroxyethyl)-1-piperazineethanesulfonic acid; Iba-1, ionized calcium-binding adapter molecule 1; IC $\mathrm{C}_{50}$, half maximal inhibitory kinase; IFN- $\gamma$, interferon $\gamma$; IL-17, interleukin-17; IL-1 $\beta$, interleukin 1 $\beta$; IL-6, interleukin-6; i.t., intrathecal injection; i.p., intraperitoneal injection; L5, lumbar 5; MAPK, mitogen activated protein kinase; MAP2, microtubule-associated protein 2; mEPSC, miniature excitatory postsynaptic current; mRNA, messenger ribo nucleic acid; NeuN, neuron specific nuclear protein; NMDA, N-methyl-D-aspartate; NR1, NMDA receptor 1; NR2B, NMDA receptor 2B; PBS, phosphate buffered saline; pNR1, phosphorylated NR1; pNR2B, phosphorylated NR2B; PSNL, partial sciatic nerve ligation; PVDF, polyvinylidene difluoride; RT-PCR, reverse transcription polymerase chain reaction; SE, standard error; SG neuron, substantia gelatinosa neuron; siRNA, small interfering ribo nucleic acid; sEPSC, spontaneous excitatory postsynaptic current; TCA-3, thymus-derived chemotactic agent 3; TNF- $\alpha$, tumour necrosis factor- $\alpha$; TTX, tetrodotoxin; VGAT, vesicular GABA transporter; VGLUT1, vesicular glutamate transport protein 1

Received 11.1.13; revised 03.4.13; accepted 24.4.13; Edited by D Bano
} 
There are many reports that nerve injury triggers reactive changes in peripheral immune system and in neuroglial cells in both peripheral and central nervous systems. ${ }^{4,11,12}$ In the periphery, activation of Schwann cells and resident macrophages recruit hematogenous immune cells, which subsequently invade the injured nerves. ${ }^{12-14}$ In the spinal dorsal horn receiving the injured sensory afferents, activation of microglia is commonly associated with early establishment stages of neuropathic pain. ${ }^{2,15,16}$ Cytokines such as interleukin-1 $\beta$ (IL-1 $\beta)$, tumour necrosis factor- $\alpha$ (TNF- $\alpha$ ) and IL-6, which originate from the peripheral injured area or from activated neuroglial cells in the spinal cord, are known to alter synaptic transmission in the dorsal horn. ${ }^{13,14}$

Chemokines and their receptors are widely expressed in immune cells and in the nervous system. ${ }^{17,18}$ Recent studies have shown that chemokines $\mathrm{C}-\mathrm{C}$ motif ligand 2 (CCL-2) and CX3CL-1 induce tactile allodynia (when non-painful innoxious stimuli become painful) through activation of spinal cord microglia. ${ }^{17,19}$ These reactive changes mediated through cytokines and chemokines develop in parallel with tactile allodynia, the latter being the main symptom of neuropathic pain. ${ }^{20}$

CCL-1 (also known as thymus-derived chemotactic agent 3 ) is one of the well-characterized chemokines and is classified into the same CC chemokine group as CCL-2. CCL1 is secreted by activated T cell, mast cells and endothelial cells and has important role as the chemoattractant for neutrophils and monocytes. ${ }^{21}$ Although effects of CCL-1 on the immune cells are well characterized, the roles of CCL-1 in the central nervous system, and especially in the development of neuropathic pain, remain unclear. In this report, we found that CCL-1 is involved in the development of tactile allodynia following peripheral nerve injury through enhancement of spinal nociceptive transmission and activation of glial cells with subsequent release of cytokines.

\section{Results}

Expression of CCL-1 in the spinal cord in neuropathic mice. We first examined the development of allodynia in a partial sciatic nerve ligation (PSNL) model. Mice showed a significant increase in withdrawal response to mechanical stimulus in the ipsilateral hind-paw (tactile allodynia) at 7 days after PSNL. The pain score in the ipsilateral hind-paw was $7.5 \pm 0.8 \quad(n=8)$, while contralateral hind-paw was $1.9 \pm 0.6(n=8)$ (Figure 1a). In parallel, the protein level of CCL-1 significantly increased 7 days after PSNL in the ipsilateral spinal cord (relative protein level, $0.14 \pm 0.01$; $n=4$ ) compared with the contralateral spinal cord (relative protein level, $0.10 \pm 0.01 ; n=4$ ) (Figure $1 b$ ). On the other hand, levels of other cytokines, TNF- $\alpha$, interferon- $\gamma$ and IL- $1 \beta$ a
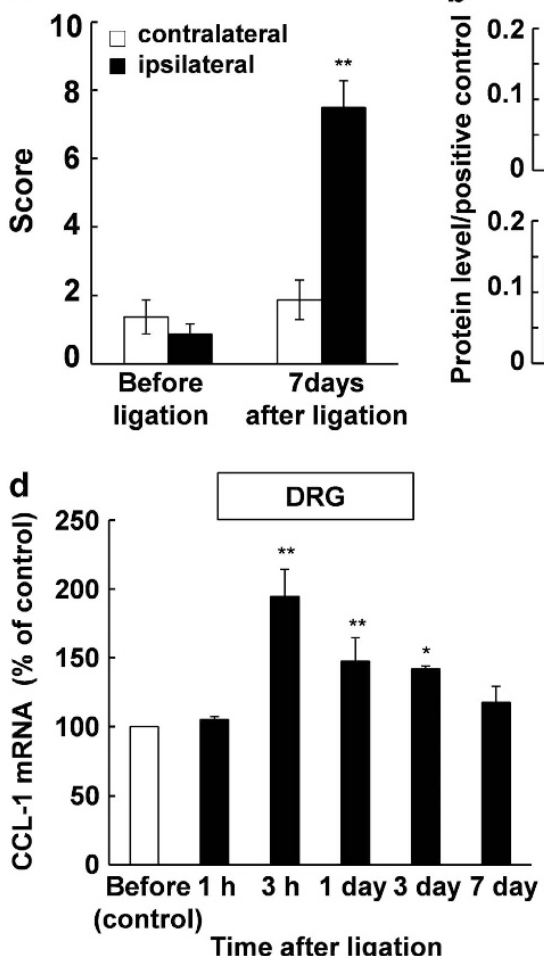

b contralateral $\square$ ipsilateral c
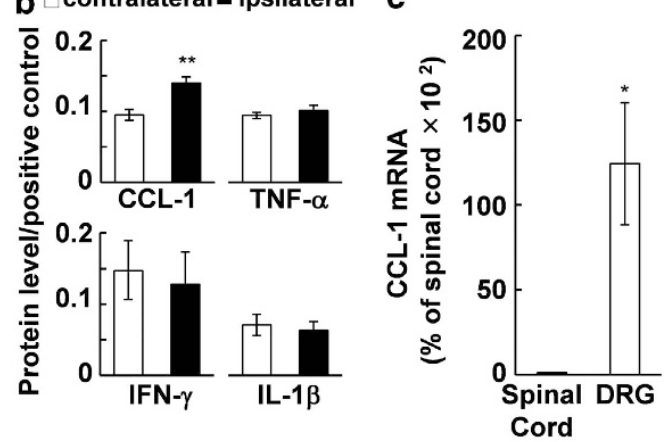

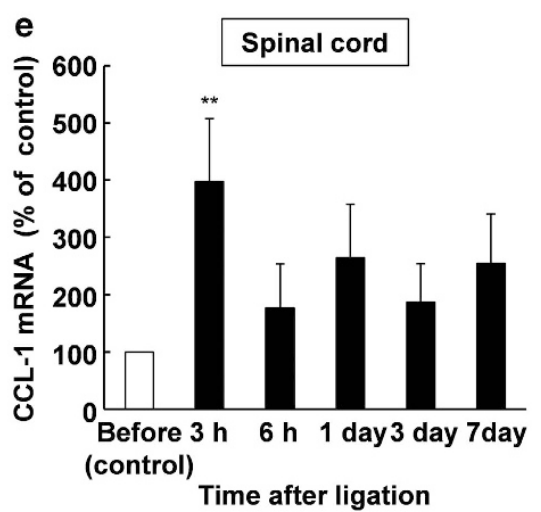

Figure 1 Increase in CCL-1 in the spinal cord after nerve ligation. (a) Mice showed tactile allodynia in the ipsilateral hind-paw at 7 days after PSNL. Data represent mean \pm S.E. $(n=8)$. ${ }^{*} P<0.01$ : versus before ligation contralateral (two-way analysis of variance (ANOVA) followed by Tukey-Kramer test). (b) Cytokine arrays on spinal cord samples at 7 days after nerve ligation. The relative values of cytokine and chemokine proteins were normalized to positive control values in the array Kit. Data represent mean \pm S.E. $(n=4)$. ${ }^{*} P<0.01$ : versus contralateral (two-tailed Student's paired $t$-test). (c) Comparing CCL-1 mRNA between spinal cord and DRG. Data represent mean \pm S.E. $(n=4) .{ }^{*} P<0.05$ : versus spinal cord (two-tailed Student's paired $t$-test). (d) Time course of CCL-1 mRNA levels in the DRG after nerve ligation was evaluated by quantitative reverse transcriptase (RT)-PCR. (e) Time course of CCL-1 mRNA levels in the spinal cord after nerve ligation was evaluated by quantitative RT-PCR. Data represent mean \pm S.E. $(\mathbf{d}, n=4 ; \mathbf{e}, n=6) .{ }^{* \star} P<0.01,{ }^{*} P<0.05$ : versus before ligation (one-way ANOVA followed by Bonferroni test) 
were not significantly changed 7 days after nerve ligation (Figure 1b).

Time course of CCL-1 mRNA expression in the spinal cord and dorsal root ganglion (DRG) after nerve ligation. First, we compared CCL-1 mRNA between the spinal cord and DRG before nerve ligation. CCL-1 mRNA was expressed in DRG $(12428 \pm 3606.7 \% ; n=4)$ more than the spinal cord (Figure 1c). Next, we examined the expression of CCL-1 mRNA in a PSNL model. CCL-1 mRNA level significantly increased at $3 \mathrm{~h}, 1$ and 3 days (194.4 $\pm 19.9 \%$, $147.3 \pm 17.3 \%, 142.0 \pm 2.0 \%$, respectively; $n=4$ ) after nerve ligation in the DRG (Figure 1d). In the spinal cord, CCL-1 mRNA level significantly increased at $3 \mathrm{~h}$ after nerve ligation $(361.1 \pm 74.5 \% ; n=6$; Figure $1 \mathrm{e})$.

Time course of CCR-8 protein expression in the spinal cord. CCR-8 is a specific receptor for CCL-1. ${ }^{22}$ Nerve ligation increased protein levels of CCR-8 in the ipsilateral dorsal spinal cord $6 \mathrm{~h}$ after surgery (Figures $2 \mathrm{a}$ and $\mathrm{c}$ ). The relative protein level of CCR-8 compared with $\beta$-actin also showed significant increase at $6 \mathrm{~h}$ after ligation (relative protein level, $0.9 \pm 0.1 ; n=9$; Figure $2 b$ ). We performed co-staining of CCR8 with neuronal or glial markers $6 \mathrm{~h}$ after nerve ligation in the spinal cord. Increased expression of CCR-8 was observed not only in neurons but also in microglia and astrocytes in the ipsilateral side (Figure 3). In addition, we showed that CCR-8 was expressed not only on glutamatergic neurons but also on GABAergic neuronal fibers in primary cultured neurons (Supplementary Figure S1).

Injection of a neutralizing antibody against CCL-1 inhibited nerve ligation-induced allodynia. To examine the prophylactic effect of blocking CCL-1 against tactile allodynia, a neutralizing antibody against CCL-1 (anti-CCL-1, 2.5, 25 and $50 \mathrm{ng}$ ) was injected i.t. $10 \mathrm{~min}$ before nerve ligation and for 6 consecutive days after nerve ligation. The injection of 50 ng anti-CCL-1 antibody significantly reduced tactile allodynia in 3, 5 and 7 days after nerve ligation (pain score at each time point, $5.2 \pm 0.8,6.0 \pm 0.8$ and $6.0 \pm 0.9 ; n=15$, respectively; Figure $4 a$ ). The inhibition by prophylactic administration of antiCCL-1 antibody was concentration-dependent (Figure 4b). In order to test the effects of post-chronic administration, daily injection of anti-CCL-1 antibody was started 3 days after nerve ligation and continued for 7 days. Unlike prophylactic administration, the tactile allodynia was not blocked once it was induced by nerve ligation (Figure 4c).

Injection of CCL-1 induced allodynia, which was attenuated by NMDAR inhibitor. We next examined the
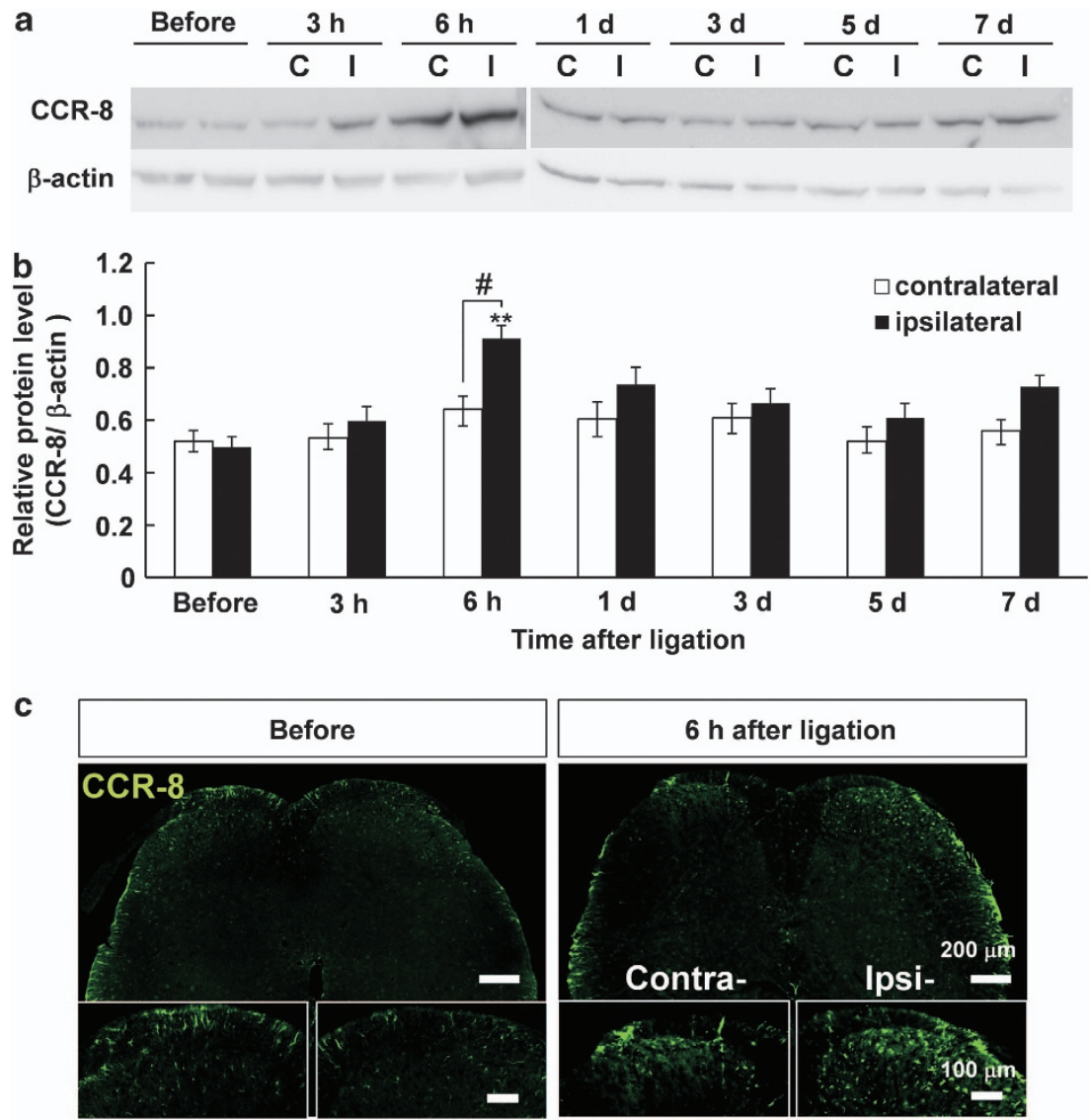

Figure 2 Expression of CCR-8 in the spinal cord following nerve ligation. (a and $\mathbf{b})$ Protein levels of CCR-8, a selective receptor for CCL-1, in the spinal cord at different time points after nerve ligation were evaluated by western blotting. $C$, contralateral;, ipsilateral. Data represent mean \pm S.E. (b, $n=9)$. ${ }^{* *} P<0.01$ : versus ipsilateral before ligation, ${ }^{\#} P<0.05$ : versus contralateral (two-way analysis of variance followed by Tukey-Kramer tests). (c) Immunostaining for CCR-8 in contralateral (Contra-) and ipsilateral (Ipsi-) spinal cord before and $6 \mathrm{~h}$ after nerve ligation. Bars $=200 \mu \mathrm{m}$ (upper panels), $100 \mu \mathrm{m}$ (lower panels) 


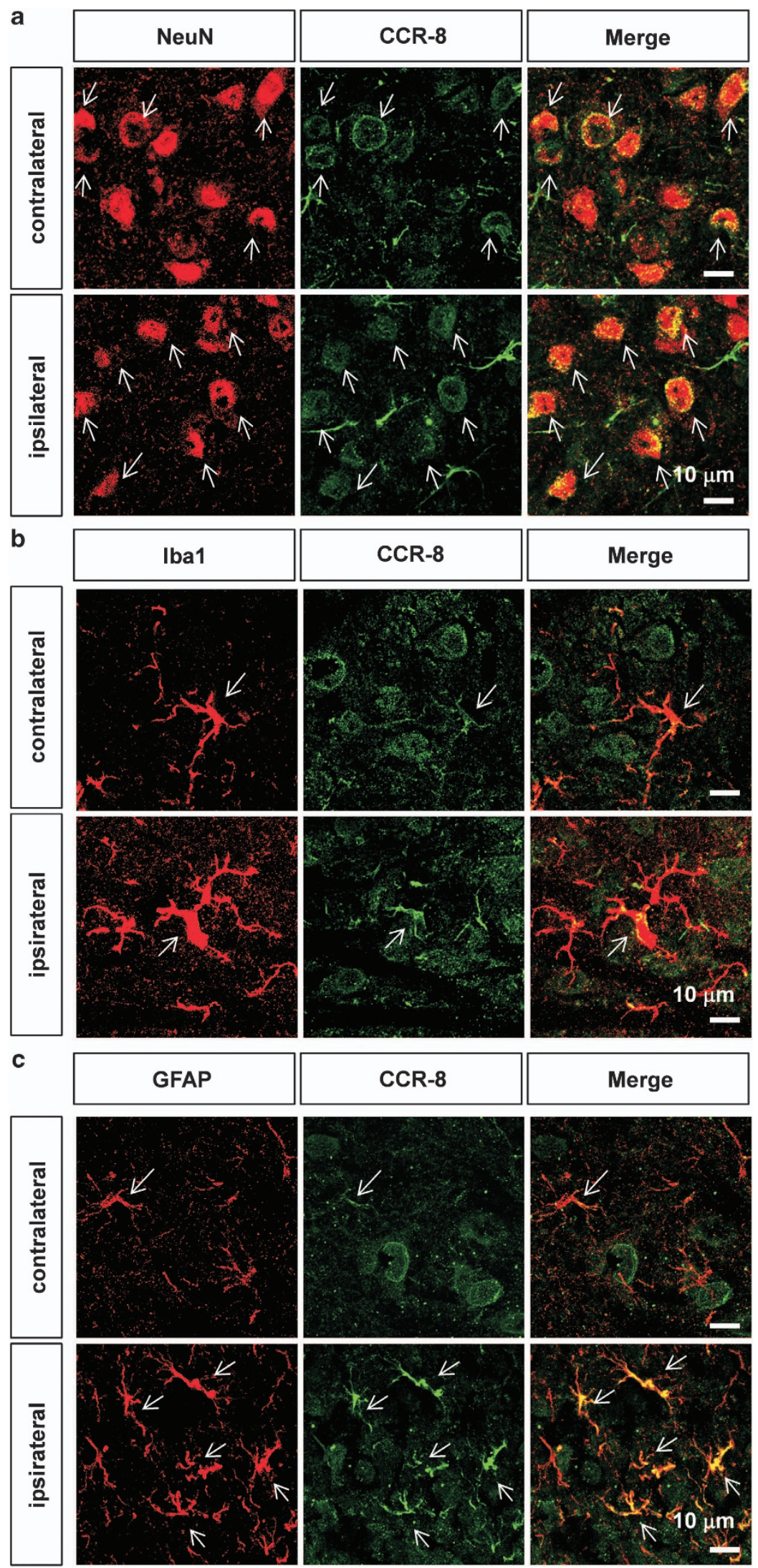

Figure 3 CCR-8 expression in neurons, microglia and astrocytes after nerve ligation. (a) Immunostaining for NeuN (red) and CCR-8 (green) $6 \mathrm{~h}$ after nerve ligation in the spinal cord. Bars $=10 \mu \mathrm{m}$. (b) Immunostaining for Iba1 (red) and CCR-8 (green) $6 \mathrm{~h}$ after nerve ligation in the spinal cord. Bars $=10 \mu \mathrm{m}$. (c) Immunostaining for GFAP (red) and CCR-8 (green) $6 \mathrm{~h}$ after nerve ligation in the spinal cord. Bars $=10 \mu \mathrm{m}$ 
a

Prophylactic and chronic administration
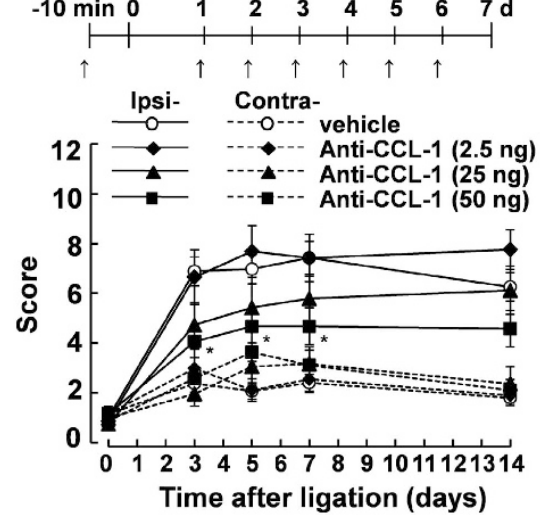

Time after ligation (days)
C

Post-chronic administration
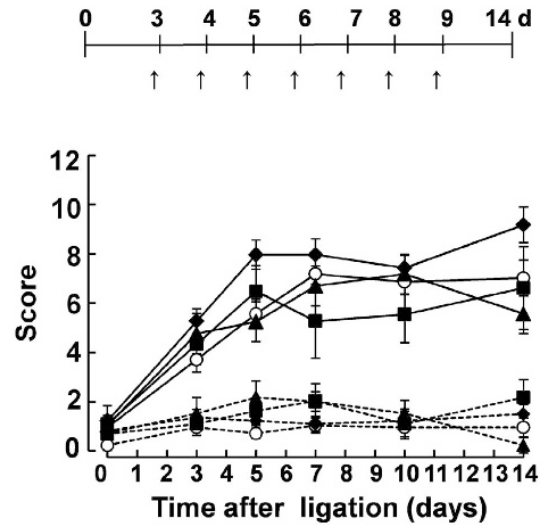

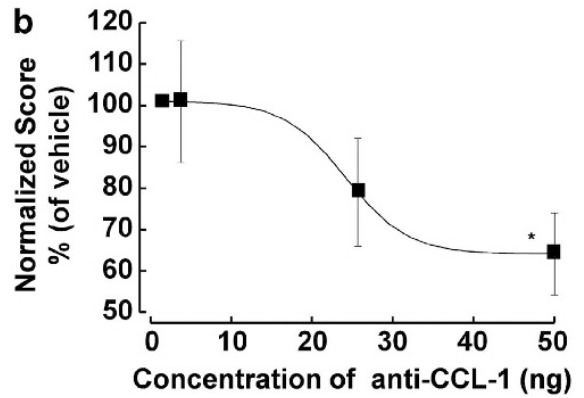

Figure 4 Inhibition of ligation-induced allodynia by neutralizing antibody against CCL-1. (a and $\mathbf{c}$ ) Effects of CCL-1 neutralizing antibody (anti-CCL-1) on allodynia induced by nerve ligation. CCL-1 neutralizing antibody (anti-CCL-1) or vehicle (control serum) was first injected 10 min before nerve ligation (a) or 3 days after nerve ligation (c), followed by daily administration (shown by arrows). Scores were measured using a von Frey filament (vehicle, $n=17$; each concentration of anti-CCL-1, $n=15$ ). $0=$ before ligation. (b) Concentration-dependent inhibition of allodynia by anti-CCL-1 antibody 7 days after nerve ligation by the method of prophylactic and chronic administration. Each data represent mean \pm S.E. ${ }^{*} P<0.05$ : versus vehicle (two-way analysis of variance followed by Tukey-Kramer test)

effect of an intrathecal (i.t.) injection of CCL-1 on nociceptive behaviour. The effect of CCL-1 was dose- and time-dependent; $25 \mathrm{ng}$ CCL-1 significantly increased the pain score after 10, 20, 30,40 and $80 \mathrm{~min}$ (pain score at each time point, $8.6 \pm 1.2$, $11.3 \pm 1,11.4 \pm 1.7,11.6 \pm 0.9,9.2 \pm 1.4$ and $7.4 \pm 0.9$, respectively; $n=8$; Figure 5a). The pain score $20 \mathrm{~min}$ after i.t. injection of different concentration of CCL-1 is presented in Figure $5 \mathrm{~b}$. NMDARs are critical in pathogenesis of allodynia. ${ }^{5,6}$ In our model, the allodynia induced by i.t. injection of CCL-1 (25 ng) was dose-dependently blocked by co-injection of MK-801, a non-competitive use-dependent NMDAR antagonist, at concentration of 125,250 and $500 \mathrm{pM}$ (Figure 5c). MK-801 showed dose-dependent inhibition of allodynia induced by CCL-1 at 10, 20, 30, 40 and 50 min after injection (pain score at each time point, $3.0 \pm 0.7,4.6 \pm 0.7,6.4 \pm 1.0,4.3 \pm 0.8$, $4.0 \pm 0.7$, respectively; $n=8$; Figure $5 \mathrm{c}$ ). The $\mathrm{IC}_{50}$ for MK-801 effects was $354 \mathrm{pM}(n=8)$ when determined in 20 min after i.t. injection of CCL-1 (Figure $5 \mathrm{~d}$ ), suggesting the role of NMDAmediated transmission in allodynia.

CCL-1 increased glutamate release in the superficial dorsal horn of the spinal cord. We examined the action of CCL-1 on excitatory synaptic transmission in the superficial spinal dorsal horn, in the substantia gelatinosa (lamina II), by using whole-cell patch-clamp recordings from mouse spinal cord slices. When holding the cell at $-70 \mathrm{mV}$, substantia gelatinosa neurons exhibited spontaneous excitatory postsynaptic currents (sEPSCs) with average frequency of $7.1 \pm 1.0 \mathrm{~Hz}$ and amplitude of $11.4 \pm 0.9 \mathrm{pA}(n=9)$. In four of the nine cells examined, bath application of CCL-1 $(50 \mathrm{ng} / \mathrm{ml})$ for $60-90 \mathrm{~s}$ enhanced the excitatory synaptic transmission as shown in Figure 5e; this action lasted for more than 3-5 min. In the CCL-1-sensitive cells, the frequency and amplitude of SEPSCs in the presence of CCL- 1 were $174 \pm 11 \%$ and $110 \pm 6.3 \%$ of controls, respectively (Figure $5 \mathrm{e})$. In the presence of TTX $(1 \mu \mathrm{M})$, such excitatory effect of CCL-1 was also detected in two out of the six cells tested (data not shown).

NMDAR phosphorylation after injection of CCL-1 in the spinal cord. We examined whether CCL-1 induced phosphorylation of NR1 and NR2B subunits of NMDAR in the spinal cord using western blotting (Figures $6 a$ and b). CCL-1 affected phosphorylation levels of NR1 subunit at Ser896 ( $p$-NR1) in the spinal cord at $3 \mathrm{~h}, 1$ and 3 days after injection of CCL-1 (25 ng, i.t.) (relative protein levels, $2.7 \pm 0.75$, $4.5 \pm 1.16$, $3.5 \pm 0.88$, respectively; $n=3$; Figure $6 \mathrm{c}$ ). After immunoblotting, the membrane was stripped and reprobed with anti-NR1 antibody (Figure 6a). However, CCL-1 had no effect on the increase of NR1 protein level (Figure 6d). The protein level of $\mathrm{p}-\mathrm{NR} 1 / \mathrm{NR} 1$ was increased at 1, 3h, 1 and 3 days after injection of CCL-1 (25 ng, i.t.) (relative protein levels, $5.5 \pm 0.69,5.5 \pm 1.32,9.8 \pm 1.84,7.3 \pm 1.46$, respectively; $n=3$; Figure 6e). CCL-1 induced phosphorylation of 
a
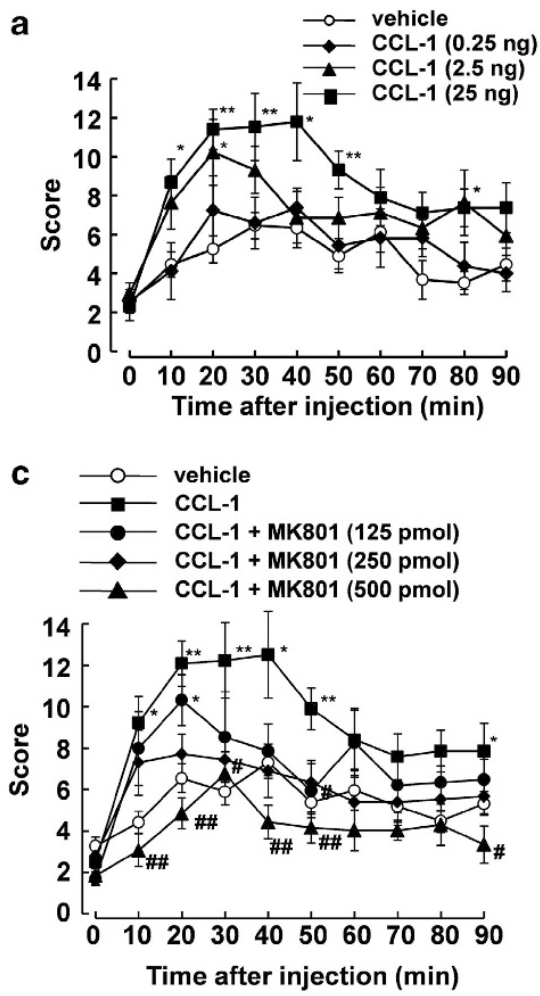

e

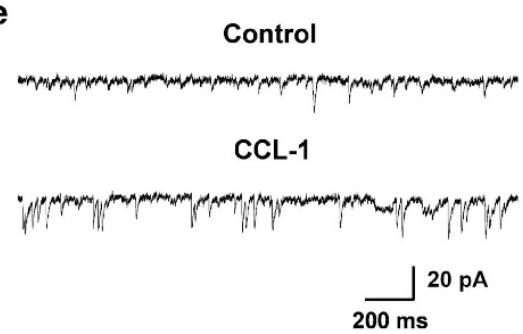

b

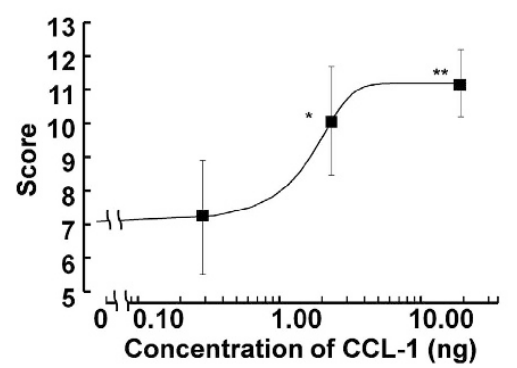

Figure 5 Induction of allodynia by CCL-1 and attenuation of CCL-1-induced allodynia by NMDA antagonist and effect of CCL-1 on excitatory synaptic transmission in the superficial spinal dorsal horn. (a) Intrathecal (i.t.) injection of CCL-1 to naive mice induced allodynia (vehicle, $n=12$; each concentration of CCL-1, $n=8$ ). (b) Concentration dependence of CCL-1-induced allodynia 20 min after i.t. injection of CCL-1. (c) Co-injection of MK-801 blocked allodynia induced by CCL-1 (25 ng, i.t.) (vehicle, $n=12$; each concentration of MK-801, $n=8$ ). (d) Concentration-dependent inhibition of allodynia by MK-801 50 min after injection. The concentration of MK-801 for $50 \%$ inhibition (IC 50 ) was $354 \mathrm{pmol}$. Data represent mean \pm S.E. ${ }^{* *} P<0.01$, ${ }^{*} P<0.05$ versus vehicle; ${ }^{\# \#} P<0.01$, ${ }^{\#} P<0.05$ : versus $C$ CL- 1 ( $25 \mathrm{ng}$ ) (two-way analysis of variance followed by Tukey-Kramer tests). (e) Representative excitatory effect of CCL-1 $(50 \mathrm{ng} / \mathrm{ml})$ on sEPSCs evoked in substantia gelatinosa neurons at a holding potential of $-70 \mathrm{mV}$ (the left traces). CCL-1 elicited a barrage of SEPSCs. The excitatory action of CCL-1 was detected in about $40 \%$ of neurons tested (see Result section). Graphs in the right show CCL-1 actions on the frequency and amplitude of SEPSCs $(n=9)$

NR2B subunit at Tyr1472 (p-NR2B) in the spinal cord at 1 and $3 \mathrm{~h}$ after injection of CCL-1 ( $25 \mathrm{ng}$, i.t.) (relative protein levels, $2.4 \pm 0.24,4.7 \pm 0.18$, respectively; $n=3$; Figure $6 f)$. After immunoblotting, the membrane was stripped and reprobed with anti-NR2B antibody (Figure 6b). CCL-1 increased level of NR2B protein at 1,3 and 7 days after injection of CCL-1 ( $25 \mathrm{ng}$, i.t.; relative protein levels, $2.9 \pm 0.33,2.9 \pm 0.35$, $3.2 \pm 0.65$, respectively; $n=3$; Figure $6 \mathrm{~g}$ ). The protein level of $p$-NR2B/NR2B was increased at 1 and $3 \mathrm{~h}$ after injection of CCL-1 ( $25 \mathrm{ng}$, i.t.; relative protein levels, $0.90 \pm 0.34$, $0.97 \pm 0.34$, respectively; $n=3$; Figure $6 \mathrm{~h}$ ).

Effects of CCL-1 injection on glial cells and cytokines in the spinal cord. Activation of glial cells contributes to the development and maintenance of tactile allodynia. ${ }^{11,13} \mathrm{We}$ examined microglia and astrocytes in the spinal cord after injection of CCL-1 ( $25 \mathrm{ng}$, i.t.). Iba1 mRNA levels significantly increased in the spinal cord at $1,3 \mathrm{~h}$ and 1 day after injection of CCL-1 ( $25 \mathrm{ng}$, i.t.; $179.8 \pm 12.0,168.4 \pm 20.0$, $149.5 \pm 20.0 \%$, respectively; $n=4$; Figure 7a). And we showed that CCL-1 ( $25 \mathrm{ng}$, i.t.) induced increase and morphological change of Iba1-positive microglia 1 day after injection (Supplementary Figure S3). CD11b mRNA levels also significantly increased in the spinal cord at 1 day after injection of CCL-1 (25 ng, i.t.; $249.5 \pm 51.2 \% ; n=4$; Figure $7 \mathrm{~b}$ ). It was reported that $\mathrm{P} 2 \mathrm{X}_{4} \mathrm{R}$ on microglia are important for the development of neuropathic pain. ${ }^{2,3} \mathrm{We}$ examined the expression of $\mathrm{P} 2 \mathrm{X}_{4} \mathrm{R}$ mRNA after injection of CCL-1 (25 ng, i.t.). However, P2X ${ }_{4}$ R mRNA had not changed after injection of CCL-1 (Figure 7c). Glial fibrillary acid protein 

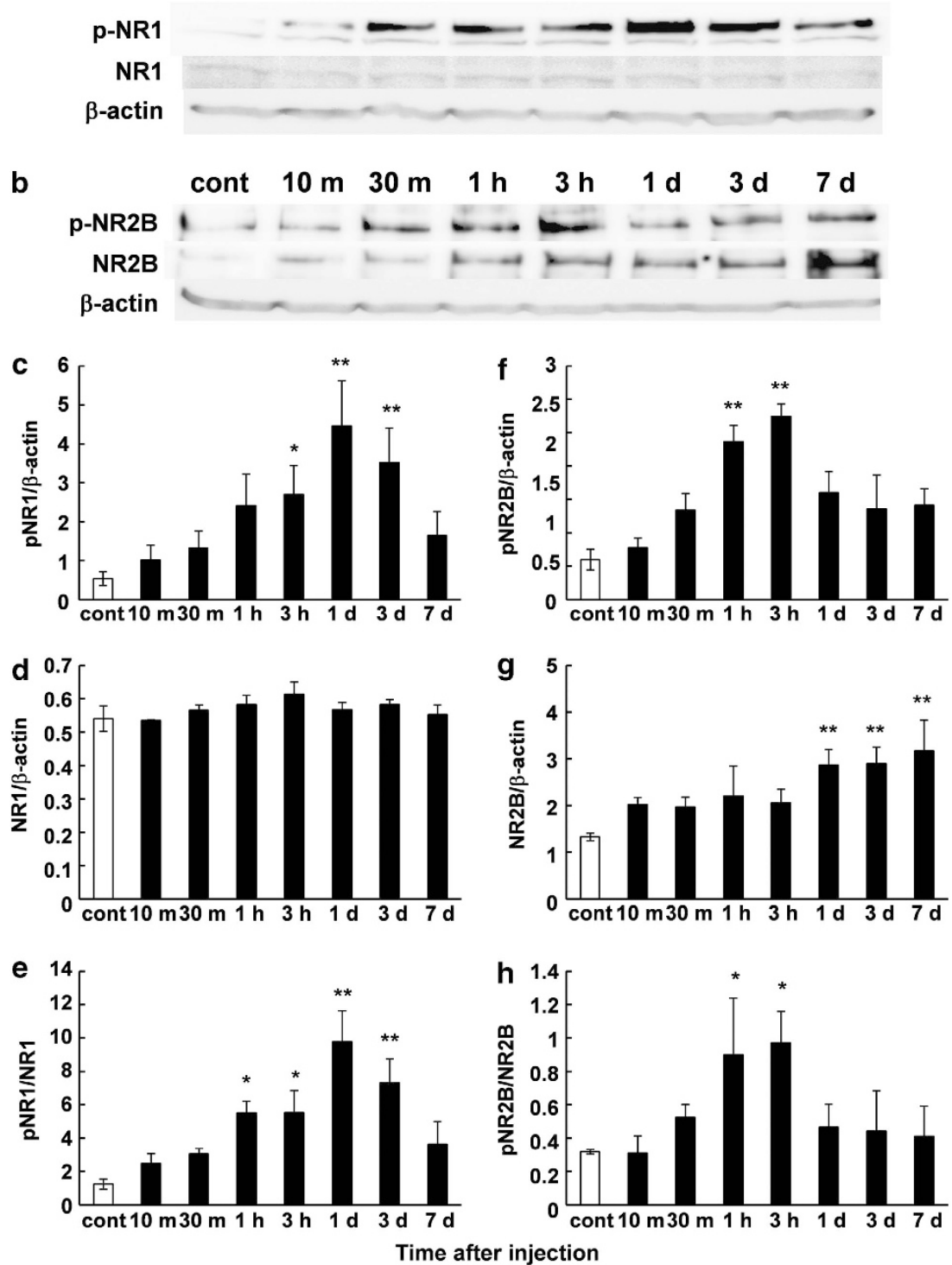

Figure 6 NMDAR phosphorylation after injection of CCL-1 in the spinal cord. (a) The phosphorylation levels of NR1 subunit at Ser896 (p-NR1) in the spinal cord at different time points after injection of CCL-1 (25 ng, i.t.) were evaluated by western blotting. The membrane was stripped and reprobed with anti-NR1 antibody. (b) The phosphorylation levels of NR2B subunit at Tyr1472 (p-NR2B) in the spinal cord at different time points after injection of CCL-1 (25 ng, i.t.) were evaluated by western blotting. The membrane was stripped and reprobed with anti-NR2B antibody. (c) The graph summarizes the protein level of $p$-NR1. (d) The graph summarizes the protein level of NR1. (e) Comparison of the levels of p-NR1 normalized to NR1. (f) The graph summarizes the protein level of p-NR2B. (g) The graph summarizes the protein level of NR2B. (h) Comparison of the levels of $p$-NR2B normalized to NR2B. Data represent mean \pm S.E. $(n=3) .{ }^{* *} P<0.01,{ }^{*} P<0.05$ : versus control (cont) (one-way analysis of variance followed by Bonferroni's test)

(GFAP) mRNA level significantly increased in the spinal cord at $1,3 \mathrm{~h}$ and 1 day after injection of CCL-1 (25 ng, i.t.; $199.1 \pm 19.0,163.5 \pm 16.6,169.7 \pm 20.8 \%$, respectively; $n=4$; Figure $7 d$ ). In addition, we observed that CCL-1 (25 ng, i.t.) induced morphological change and the number of GFAPpositive astrocytes 1 day after injection (Supplementary Figure S3). Furthermore, we examined activation of microglia and astrocytes after injection of CCL-1 (25 ng, i.t.) using phosphorp38 MAPK antibody (p-p38). CCL-1 induced phosphorylation of p38 MAPK on microglia and astrocytes (Supplementary Figure S2). Cytokines and growth factors are important mediators of neuronal-glial interactions. ${ }^{12,23}$ We examined cytokine (IL-1 $\beta$,
TNF- $\alpha$, IL-6) and brain-derived neutrophic factor (BDNF) in the spinal cord after injection of CCL-1 (25 ng, i.t.). Though protein levels of IL- $1 \beta$, TNF- $\alpha$ and IL- 6 were not changed after 7 days of nerve ligation (Figure 1b), IL-1 $\beta$ mRNA significantly increased in the spinal cord at 1 and $3 \mathrm{~h}$ after injection of CCL-1 (25 ng, i.t.; $688.0 \pm 150.8,609.2 \pm 148.1 \%$, respectively; $n=4$; Figure $7 \mathrm{e}$ ), as well as TNF- $\alpha \mathrm{mRNA}$ at $30 \mathrm{~min}, 1$ and $3 \mathrm{~h}$ (25 ng, i.t.; $368.1 \pm 150.1$, $485.8 \pm 94.4$, $408.1 \pm 97.4 \%$, respectively; $n=4$; Figure 7f), and IL- 6 mRNA at 1 and $3 \mathrm{~h}$ ( $25 \mathrm{ng}$, i.t.; $248.7 \pm 40.8$, $318.0 \pm 68.8 \%$, respectively; $n=4$; Figure $7 \mathrm{~g}$ ) after injection of CCL-1. On the other hand, BDNF mRNA did not change after injection of CCL-1 (Figure $7 \mathrm{~h}$ ). 
a
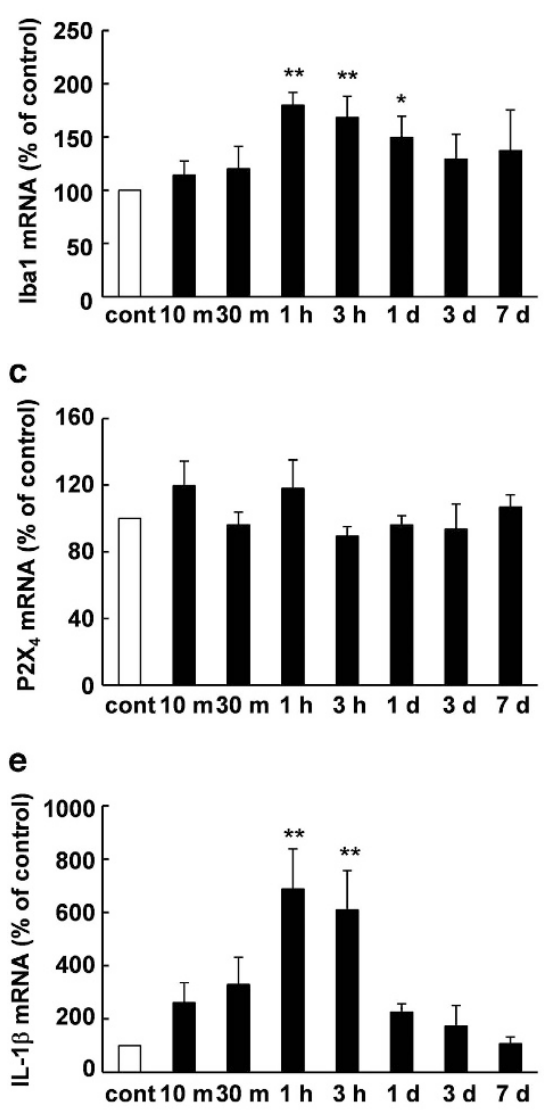

g

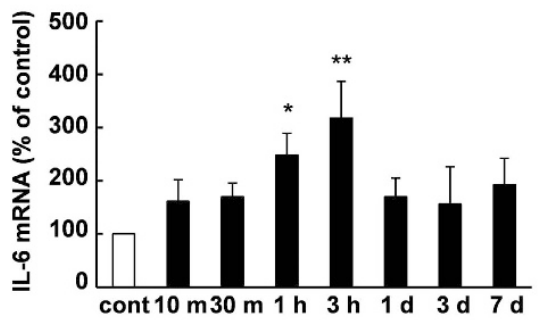

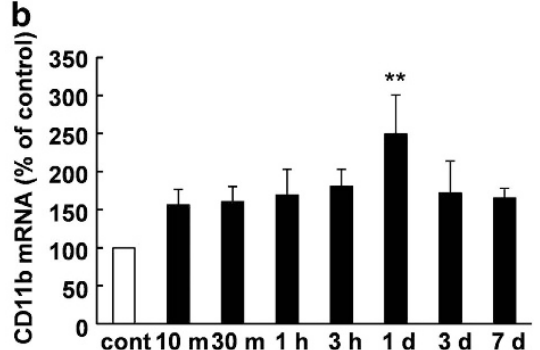
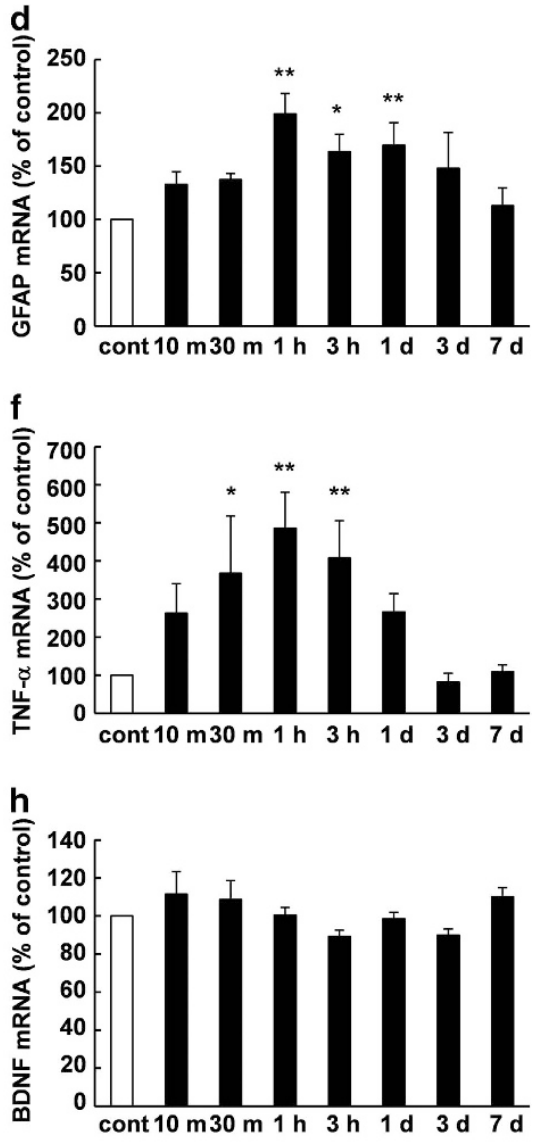

Time after injection

Figure 7 CCL-1 increased the expression of glial cells and cytokines in the spinal cord. Expression of mRNA of (a) Iba1, (b) CD11b, (c) P2X $\mathrm{X}_{4}$, (d) GFAP, (e) IL-1 $\beta$, (f) TNF- $\alpha$, (g) IL-6 and (h) BDNF after injection of CCL-1 (25 ng, i.t.) were evaluated by RT-PCR. Each value was normalized to the control level (cont). Data represent mean \pm S.E. $(n=4) .{ }^{* \star} P<0.01,{ }^{*} P<0.05$ : versus control (one-way analysis of variance followed by Bonferroni's test)

Effects of i.t. CCR-8 siRNA treatment on allodynia. We next examined the effects of CCR-8 downregulation on tactile allodynia. We made CCR-8 knockdown model using transfection of siRNA against CCR-8. We confirmed that protein level of CCR-8 was reduced in the spinal cord 5 days after injection of CCR-8 siRNA (Figure 8a). The CCR-8 knockdown mice were subjected to PSNL 5 days after injection of CCR-8 siRNA. We examined the effect of CCR-8 knockdown on allodynia and coordinated motion using von Frey filament test and rota-rod test. Downregulation of CCR-8 reduced PSNL-induced tactile allodynia for 2 weeks $(n=5$; Figure $8 \mathrm{c})$. By contrast, downregulation of CCR-8 had no effect on coordinated motion ( $n=5$; Figure $8 \mathrm{~d})$.

\section{Discussion}

The present study, for the first time, demonstrates that expression of CCL-1 in the spinal cord and DRG at the mRNA and protein levels is increased after nerve ligation, and the nerve ligation-induced tactile allodynia is attenuated by treatment with neutralizing antibody against CCL-1 and in CCR-8 knockdown mice. We further show that CCL-1 has an excitatory action on the glutamatergic synaptic transmission and phosphorylation of NMDAR subunits, NR1 and NR2B, in the spinal dorsal horn and increase expression of glial cells activation markers (Iba1, CD11b and GFAP) and cytokines (IL-1 $\beta$, TNF- $\alpha$ and IL-6). Our results therefore indicate that CCL-1 may be one of the key mediators of chronic tactile 


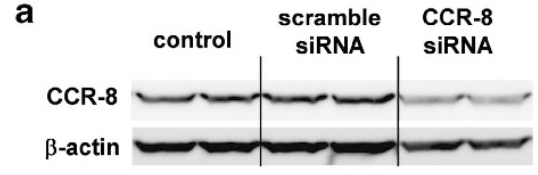

C

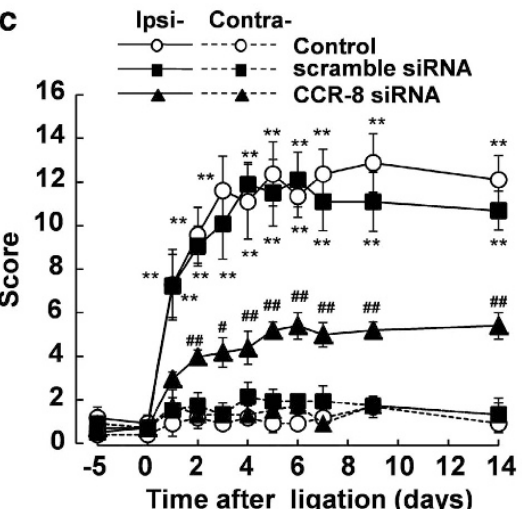

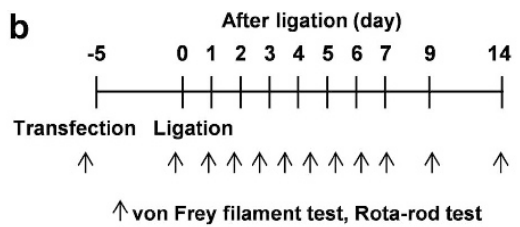

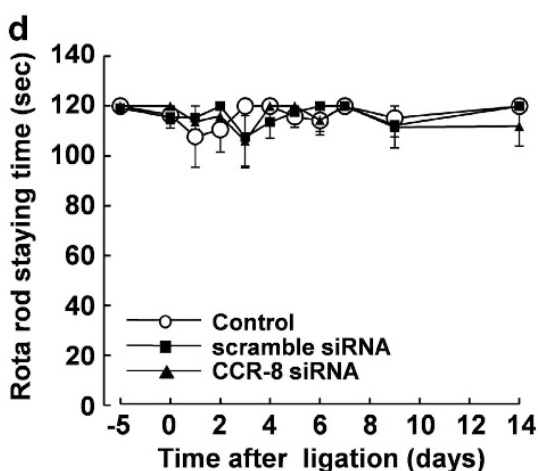

Figure 8 Intrathecal siRNA against CCR-8 treatment inhibited allodynia-induced nerve ligation. (a) Protein level of CCR-8 in the spinal cord after transfection of CCR-8 siRNA. (b) Schedule for making model mice and behavioural analysis. (c) CCR-8 siRNA inhibited allodynia-induced nerve ligation. (d) There was no change in coordinated motion after siRNA treatment. Data represent mean \pm S.E. $(n=5)$. ${ }^{\star \star} P<0.01$ versus contralateral; ${ }^{\#} P<0.01,{ }^{\#} P<0.05$ : versus scramble siRNA (two-way analysis of variance followed by Tukey-Kramer tests)

allodynia acting through an acute modulation of nociceptive synaptic transmission, phosphorylation of NR1 and NR2B, glial activation and increase of cytokines in the spinal cord.

In this study, we showed that CCL-1-specific receptor, CCR-8, was expressed in not only neurons but also glial cells $6 \mathrm{~h}$ after nerve ligation in the ipsilateral side (see Figure 3 ). We suggested that increase of total CCR-8 protein after nerve ligation in the spinal cord by increase of CCR-8 expression on glial cells. CCL-1 mRNA showed only a transient increase in the spinal cord (see Figure 1e) and at $3 \mathrm{~h}, 1$ and 3 days after nerve ligation in DRG (see Figure 1d). This indicates that CCL-1 may be mainly produced in DRG after nerve ligation. In the case of CCL-21 and CCL-2, they were produced in DRG after nerve ligation and were transported to neuronal terminals in the dorsal horn. ${ }^{24,25} \mathrm{CCL}-2$ was released from neuronal synaptic vesicles in the spinal cord. ${ }^{26}$ Similarly, we assume that CCL-1, which is produced in DRG neurons after nerve ligation, is subsequently transported to the spinal cord and then released. CCL-1 mRNA in the spinal cord at $3 \mathrm{~h}$ after nerve ligation was also produced in glial cells albeit only transiently; this however, requires further investigation.

Immune cells and glial cells interact with neurons to alter pain sensitivity and to mediate the transition from acute to chronic pain. ${ }^{11,14,19}$ It is generally believed that microglia are involved in the development and astrocytes in the maintenance of neuropathic pain. ${ }^{27-29}$ Cytokines are important messengers for the communication between neurons and glia. ${ }^{11,13,30}$ Injection of CCL-1 into the spinal cord increased the mRNA level of microglial (CD11b or lba1) and astroglial (GFAP) markers, as well as that of cytokines (IL-1 $\beta$, TNF- $\alpha$ and IL-6) (see Figure 7). We also observed double staining of GFAP or CD11b with p-P38 after i.t. injection of CCL-1, suggesting that microglia and astrocytes were in reactive states (see Supplementary Figure S2). Activation of microglia in the spinal dorsal horn following peripheral nerve injury is well characterized. ${ }^{2,31}$ The mechanisms of nerve injuryinduced microglial activation are complex and involve several signaling systems. ${ }^{32}$ Purinergic signaling mediated through $\mathrm{P}_{2} \mathrm{X}_{4}, \mathrm{P}_{2} \mathrm{X}_{7}$ and $\mathrm{P} 2 \mathrm{Y}_{12}$ receptors seems to contribute to the initial activation of microglia following acute nerve injury. $2,3,16,31,33,34$ We, however, failed to identify changes in $\mathrm{P} \mathrm{X}_{4}$ receptor $\mathrm{mRNA}$ in the spinal cord after injection of CCL1. This suggests that CCL-1-mediated activation of microglia does not involve the upregulation of $\mathrm{P}_{2} \mathrm{X}_{4}$ receptors but engages distinct signaling cascade(s). Several reports have previously demonstrated that cytokines and chemokines activate microglia and astrocytes, inducing secretion of proinflammatory factors (e.g., IL-1 $\beta$, TNF- $\alpha$, BDNF, IL-6, IL17, CCL-2). ${ }^{2,12,27}$ Several proinflammatory cytokines and chemokines have been implicated in altered nociceptive processing. ${ }^{12}$ TNF- $\alpha$ enhanced synaptic efficacy by increasing surface expression of AMPA receptors. ${ }^{35} \mathrm{IL}-1 \beta$ modulates sensory neuron transmission via increased release of the nociceptive neuropeptides substance $\mathrm{P}$ and calcitonin generelated peptide. ${ }^{36-38} \mathrm{IL}-1 \beta$ also induced the phosphorylation of NR1. ${ }^{39} \mathrm{IL}-6$ was reported to be involved in the development of neuropathic pain. ${ }^{40}$ By contrast, there are some reports that IL-6 has neuroprotective effect in the central nerve system. ${ }^{41}$ IL-1 $\beta$ and TNF- $\alpha$ induced IL- 6 expression in cultured neurons and astrocytes. ${ }^{42}$ According to these reports, it might be reasonable that a peak expression of IL- 6 in the spinal cord occurred later compared with that of TNF- $\alpha$ and IL- $1 \beta$ after injection of CCL-1 (see Figure $7 \mathrm{~g}$ ). These results indicate that CCL-1 is involved in the development of allodynia through glial activation and expression of cytokines. However, other signaling molecules can be also involved in the pathogenesis of neuropathic pain. Effects of CCL-1 on glial function need to be investigated in more detail in the future.

We showed that allodynia induced by injection of CCL-1 was blocked by co-injection of NMDAR antagonist. 
We assumed that CCL-1 enhanced glutamate release from presynaptic terminal or affected postsynaptic NMDARs. We confirmed that CCL-1 affected both, increasing glutamate release transiently and inducing phosphorylation of NR1 and NR2B gradually. As for the presynaptic effect, we showed that CCL-1 increased glutamate release only in some but not all neurons (see Figure 5e). Similarly, double immunostaining with anti-CCR-8 and anti-NeuN showed that CCR-8 expression was only in sub-population of neurons (see Figure 3), the reason of which requires further investigation. As for the postsynaptic effect, it is already reported that activation of NMDAR is important for initiating long-lasting changes in synapses and has been implicated in persistent pain by strengthening glutamatergic sensory transmission. ${ }^{5}$ Though we did not directly check whether postsynaptic NMDA currents were enhanced by CCL-1 or not, we observed that both phosphorylation of NMDAR and increase in the number of NMDARs take place in response to CCL-1. Phosphorylation of NMDAR is known to modulate NMDAR activity and facilitate transmission of nociceptive inputs in inflammatory and neuropathic pain models. ${ }^{39}$ Partial ligation of sciatic nerve significantly increased the phosphorylated proportion of NR1 and NR2B subunits in the dorsal horn. ${ }^{43,44}$ The phosphorylation of NR1 subunit is related to enhancement of synaptic efficacy and the development of central sensitization 7 days after nerve injury. ${ }^{45}$ On the other hand, NR2B selective antagonist attenuated neuropathic pain. ${ }^{46}$ Tyrosine phosphorylation of NR2B, but not NR2A, is associated with the development of persistent pain. ${ }^{47}$ In our experiments, CCL-1 induced phosphorylation of NR1 and NR2B albeit with different time course: Phosphorylation of NR2B was transient, whereas phosphorylation of NR1 continued for 3 days. In our behavioural experiments on pain score, injection of CCL-1 induced allodynia transiently, as phosphorylation of NR2B. As there is a report that NR2B is particularly important for pain perception, ${ }^{5}$ we speculate that phosphorylation of NR2B would be more important than phosphorylation of NR1 together with upregulation of NR2B. As for the phosphorylation of NR1, IL-1 $\beta$ was reported to induce phosphorylation of NR1. ${ }^{45,48}$ As IL-1 $\beta$ mRNA was increased in the spinal cord after injection of CCL-1 at 1 and $3 \mathrm{~h}$ (Figure 7e), we speculate that NR1 would be phosphorylated not only by CCL-1 but also by IL-1 $\beta$.

In conclusion, our study provides evidence that CCL-1 is produced mainly in DRG after nerve ligation, supposed to be transported to the spinal cord, where it increases glutamate release together with local upregulated CCL-1, and then activates glial cells and cytokine release. CCL- 1 also induced phosphorylation of NMDAR subunits, NR1 and NR2B. Treatment with neutralizing antibody against CCL-1 and CCR-8 siRNA blocked nerve ligation-induced tactile allodynia. Therefore CCL-1 is one of the key molecules in pathogenesis of allodynia, and CCL-1/CCR-8 signaling system can be a potential target for drug development in the treatment for neuropathic pain.

\section{Materials and Methods}

Animals. Male ddY mice (20-30 g, Kyudo Co. Ltd., Tosu, Saga, Japan) were used. Mice were housed at $23 \pm 2{ }^{\circ} \mathrm{C}$ with $12 \mathrm{~h}$ light: $12 \mathrm{~h}$ dark cycle (light on from 0700 to 1900 hours) and were given free access to commercial food and tap water. Experimental procedures were based on the Guidelines of the Committee for Animal Care and Use of Kyushu University, Fukuoka University and National Institute for Physiological Sciences.

Drugs. Recombinant mouse CCL-1 and neutralizing antibody CCL-1 were purchased from R\&D Systems (Minneapolis, MN, USA). MK801 was purchased from Sigma Aldrich (St. Louis, MO, USA).

PSNL. The mice were anesthetized with an intraperitoneal (i.p.) injection of pentobarbital $(65 \mathrm{mg} / \mathrm{kg})$. A PSNL was produced by tying a tight ligature with a No. 8 nylon thread around approximately 1/3-1/2 the diameter of the sciatic nerve located on the left side (ipsilateral side) based on the Seltzer method. ${ }^{49}$ On the right side (contralateral side), the nerve was exposed without ligation.

Behavioural analysis. Behavioural analysis was performed to assess the development of tactile allodynia in mice. Tactile allodynia was measured using a von Frey filament (North Coast Medical, Gilroy, CA, USA). Mice were placed in glass cages with a wire mesh bottom and allowed to habituate for at least $1 \mathrm{~h}$. A von Frey filament with bending forces of $0.16 \mathrm{~g}$ (innocuous stimulation) was pressed perpendicularly against the plantar skin of a hind-paw. The paw withdrawal responses to the mechanical stimulus were evaluated by scoring as follows: 0 , no response; 1 , lifting the hind-paw within $3 \mathrm{~s} ; 2$, lifting the hind-paw over $3 \mathrm{~s}$; and 3 , immediate flinching or licking of the hind-paw. The stimulation of the same intensity was applied seven times to each hind-paw at several seconds intervals and the total served as the pain-related score (score) in the SNL model. The behavioural data were analyzed using Origin (Microcal software Inc., Sunnyvale, MA, USA) software to determine the $\mathrm{IC}_{50}$ values.

We performed a rota-rod (KN-75 Rota-rod, Natume, Japan) test to measure motor balance and coordination. Mice were pre-trained on rota-rod apparatus for 3 days and then tested on the accelerating rod in which the speed of the spindle was 10 r.p.m. Latency until fall was automatically recorded. To eliminate stress and fatigue, mice were given a maximum cutoff latency of $120 \mathrm{~s}$.

Intrathecal injection. Intrathecal (i.t.) injection was performed using a $25-\mu$ l Hamilton syringe with a 28-gauge needle (Muranaka Medical Instruments co. LTD., Osaka, Japan), as described previously. ${ }^{50,51}$ The needle was inserted into the intervertebral space of a conscious mouse between the lumbar 5 (L5) and 6 (L6) regions of the spinal cord. A reflexive flick of the tail was considered to be an indicator of the accuracy of each injection. A volume of $5 \mu \mathrm{l}$ was used for the i.t. injections.

Immunohistochemical analyses. Mice were anesthetized by pentobarbital sodium (50 mg/kg, i.p.) and perfused transcardially with saline followed by $4 \%$ paraformaldehyde in $0.1 \mathrm{M}$ phosphate-buffered saline (PBS; $80 \mathrm{mM} \mathrm{Na} \mathrm{HPO}_{4}$, $20 \mathrm{mM} \mathrm{KH}_{2} \mathrm{PO}_{4}, 150 \mathrm{mM} \mathrm{NaCl}$, pH 7.4). The L4-L6 segment of the lumbar spinal cord was removed, postfixed in the same fixative and placed in $20 \%$ sucrose solution for $24 \mathrm{~h}$ at $4{ }^{\circ} \mathrm{C}$. Transverse L4-L6 spinal cord section (20 $\left.\mu \mathrm{m}\right)$ were sliced by a HM 550 cryostat (Micro-edge Instruments Co., Tokyo, Japan) and incubated for $1 \mathrm{~h}$ at room temperature in $5 \%$ donkey serum (Jackson Immuno Research, West Grove, PA, USA). Then, the sections were incubated with the following: NeuN (1: 200, Millipore, Bilerica, MA, USA), CCR-8 (1:500, Enzo, New York, NY, USA), Iba1 (ionized calcium-binding adapter molecule-1, 1:2000, Wako, Osaka, Japan), CD11b (1:500, Serotec, Oxford, UK), GFAP (1:800, Millipore) or p-p38 (phosphor-p38 MAPK, 1: 100, Cell Signaling Technology, Danvers, MA, USA) for $24 \mathrm{~h}$ at $4{ }^{\circ} \mathrm{C}$. The sections were incubated for $4 \mathrm{~h}$ at room temperature in the secondary antibody (IgG-conjugated Alexa Fluor 488 or 594, 1:1000, Molecular Probes, Eugene, OR, USA). Sections were mounted on coverslips with permafluor aqueous mounting medium (Thermo Scientific, Yokohama, Japan). The sections were analyzed using a fluorescence microscope (BZ9000, Keyence, Japan) and a confocal laser scanning microscope (LSM510META, Carl Zeiss, Hallbergmoos, Germany). In confocal imaging, we used a series of Z-stack images (images taken at multiple focal points of an objective lens through the $z$-axis) for $3 D$ analysis of each slice.

Cytokine array. Mouse cytokine array kit was purchased from R \& D Systems and was assessed as described previously. ${ }^{52}$ The L4-L6 segment of the lumbar spinal cord was isolated and homogenized in the lysis buffer $(10 \mathrm{mM}$ Tris- $\mathrm{HCl}$, $0.5 \mathrm{mM}$ EDTA, $0.5 \mathrm{mM}$ EGTA, $1 \%$ Triton X-100, pH 7.4) containing protease inhibitor cocktail (Sigma) and centrifuged at 15000 r.p.m. for $20 \mathrm{~min}$ at $4^{\circ} \mathrm{C}$. Each 
reaction was performed according to the protocol of the manufacturer using $20 \mu \mathrm{g}$ of protein collected from the sample. The protein sample was incubated with a blot array precoated with 40 cytokine/chemokine antibodies overnight at $4^{\circ} \mathrm{C}$. These blots were visualized using Lumi GLO Reserve Chemiluminescent Substrate Kit (Cell Signaling Technology) and quantified by a luminoimage analyzer (Fluor Chem Imaging System, Alpha Innotech Corporation, San Leandro, CA, USA).

Real-time reverse transcription (RT) PCR. The L4-L6 segment of the lumbar spinal cord and DRG were subjected to total RNA extraction according to the protocol of the manufacture and purified with QIAamp RNA Blood Mini (Qiagen, Valencia, CA, USA). The amount of total RNA concentration was measured using Smart Spec 3000 (Bio-Rad, Tokyo, Japan). Total RNA (175 ng) was converted to CDNA by reverse transcription, using random 9 mer (Takara, Otsu, Japan) and RNA PCR kit (Takara). The primers were as follows: CCL-1 primers (forward: $5^{\prime}$-TTCCCCTGAAGTTTATCCAGTGTT-3', reverse: $5^{\prime}$-TGAACC CACGTTTTGTTAGTTGAG-3'); $\beta$-actin primers (forward: $5^{\prime}$-TTGCTGACAGGATG CAGAAGGAG- $3^{\prime}$, reverse: $5^{\prime}$-GTGGACAGTGAGGCCAGGAT- $3^{\prime}$ ); TNF- $\alpha$ primers (forward: 5'-CCACCACGCTCTTCTGTCTAC-3', reverse: 5'-TGGGCTACAGGCTT GTCACT-3'); IL-1 $\beta$ primers (forward: $5^{\prime}$-CTCCATGAGCTTTGTACAAGG- $3^{\prime}$, reverse: $5^{\prime}$-TGCTGATGTACCAGTTGGGG-3'); IL-6 primers (forward: $5^{\prime}$-ACACTC CTTAGTCCTCGGCCA-3' ${ }^{\prime}$, reverse: $5^{\prime}$-CACGATTTCCCAGAGAACATGTG-3'); BDNF primers (forward: $5^{\prime}-$ TGCAGGGGCATAGACAAAAGG-3', reverse: $5^{\prime}-\mathrm{CTTA}$ TGAATCGCCAGCCAATTCTC- $3^{\prime}$ ); Iba1 primers (forward: $5^{\prime}$-CCTGATTGGAGGT GGATGTCAC-3', reverse: $5^{\prime}$-GGCTCACGACTGTTTCTTTTTTCC-3'); CD11b primers (forward: $5^{\prime}$-AATGATGCTTACCTGGGTTATGCT-3', reverse: $5^{\prime}$-TGATAC CGAGGTGCTCCTAAAAC-3'); GFAP primers (forward: $5^{\prime}$-CCAGCTTCGAGCCAA GGA-3', reverse: $5^{\prime}$-GAAGCTCCGCCTGGTAGACA-3'); and $P 2 X_{4} R$ primers (forward: 5'-TGGCCGACTATGTGGTCCCA-3', reverse: 5'-GGTTCACGGTGACG ATCATG-3'). All primers were purchased from Sigma Aldrich Japan (Tokyo, Japan). PCR amplification was undertaken for Sybr qPCR Mix (Takara) in Applied Biosystems 7500 Real-Time PCR System (Applied Biosystems Japan, Tokyo, Japan). Each reaction volume consisted of $10 \mu \mathrm{l}$ Sybr qPCR Mix, $0.4 \mu \mathrm{l} 50 \times \mathrm{ROX}$ reference dye, $0.4 \mu \mathrm{l}$ mix of forward and reverse primers $(0.2 \mu \mathrm{M}$ each) and $7.8 \mu \mathrm{l}$ RNAase free water containing CDNA (17.5 ng). PCR was done by $15 \mathrm{~s}$ denaturation at $95{ }^{\circ} \mathrm{C}$ and annealing/extending at $60^{\circ} \mathrm{C}$ for 40 cycles. Each mRNA expression level was normalized by $\beta$-actin. The mRNA expression was calculated relative to $\beta$-actin using the $\Delta \Delta \mathrm{C}_{\mathrm{T}}$ algorithm.

Western blotting. Expression protein level of CCR-8 in lumbar spinal cord was examined by western blotting relative to $\beta$-actin. The L4-L6 segments of the lumbar spinal cord were isolated and homogenized in a lysis buffer containing protease inhibitor (Sigma); subsequently $20 \mathrm{mg}$ of proteins were loaded for each lane and separated by SDS-PAGE gel $(7.5 \%)$, and transferred to PVDF membrane (Bio-Rad). The membrane was blocked with $5 \%$ low-fat dried milk (antiCKR8/CCR-8), 5\% BSA (anti-p-NR2B, anti-NR2B) or 3\% BSA (anti-p-NR1, antiNR1) and incubated with the following for $1 \mathrm{~h}$ at room temperature: Rabbit monoclonal anti-CKR8/CCR-8 (1:500, Epitomics, Burlingame, CA, USA), antiphospho-NR1 (Ser896; 1:1000, Millipore), anti-NR1 (1:1000, Millipore), antiphospho-NMDAR2B (Y1472; 1:1000, R\&D Systems), anti-NMDAR2B (D15B3) (1:1000, Cell Signaling Technology), and anti- $\beta$-actin $(1: 1000$, Sigma). The membrane was washed and incubated with specific secondary antibodies (Amersham ECL anti-rabbit IgG and anti-mouse IgG, horseradish peroxidaselinked species-specific whole antibody, 1:5000, GE Healthcare, Piscataway, NJ, USA). The blots were detected by use of ECL western blotting detection system (GE Healthcare) and LAS-4000 imaging system (Fujifilm, Tokyo, Japan). Bands were quantified using the software Multi Gauge (Fujifim).

Preparation of spinal cord acute slices. The methods used for obtaining spinal cord slice preparations are identical to those described elsewhere. ${ }^{53,54}$ Mice were anesthetized with urethane (1.2-1.5 g/kg, i.p.), and a thoracolumbar laminectomy was performed. The lumbosacral segments of the spinal cord (L1-S1) were placed in an ice-cold Krebs solution equilibrated with $95 \% \mathrm{O}_{2} / 5 \% \mathrm{CO}_{2}$. The Krebs solution contained (in $\mathrm{mM}$ ) $117 \mathrm{NaCl}, 3.6 \mathrm{KCl}, 2.5$ $\mathrm{CaCl}_{2}, 1.2 \mathrm{MgCl}_{2}, 1.2 \mathrm{NaH}_{2} \mathrm{PO}_{4}, 25 \mathrm{NaHCO}_{3}$ and 11 glucose. Immediately after removal of the spinal cord, the mice were exsanguinated under the urethane anesthesia. The pia-arachnoid membrane was removed after cutting all of the ventral and dorsal roots. The spinal cord was mounted on a vibratome and a 500$\mu \mathrm{m}$ thick transverse or sagittal slices were cut. The slice was placed on a nylon mesh in the recording chamber with a volume of $0.5 \mathrm{ml}$ and was completely submerged and perfused with Krebs solution saturated with $95 \% \mathrm{O}_{2}$ and $5 \% \mathrm{CO}_{2}$ at $36 \pm 1{ }^{\circ} \mathrm{C}$ at a flow rate of $10-15 \mathrm{ml} / \mathrm{min}$.

Whole-cell patch-clamp recordings from substantia gelatinosa neurons. The substantia gelatinosa was easily discernible with transmitted illumination as a relatively translucent band across the dorsal horn in the transverse or parasagittal slice preparations. Blind whole-cell voltage-clamp recordings were made from SG neurons, as previously described ${ }^{53,54}$ The patch pipettes were filled with potassium gluconate solution, a solution containing (in $\mathrm{mM}$ ); $135 \mathrm{~K}$-gluconate, $5 \mathrm{KCl}, 0.5 \mathrm{CaCl}_{2}, 2 \mathrm{MgCl}_{2}, 5 \mathrm{EGTA}, 5$ HEPES, and 5 ATP-Mg (pH 7.2). The tip resistance of the patch pipettes was 6-12 M $\Omega$. Series resistance was assessed from current in response to a 5-mV hyperpolarizing step. Series resistance was monitored during the recording session and data were rejected if its value changed by $>15 \%$. Ion currents were monitored with a patchclamp amplifier (Axopatch 700A, Molecular Devices, Sunnyvale, CA, USA). The data were digitized with an analog-to-digital converter (Digidata 1321A, Molecular Devices), stored on a personal computer using a data acquisition program (Clampex version 10, Molecular Devices) and analyzed using a software package Clampfit version 10 (Molecular Devices). Recordings were made in a voltageclamp mode at holding potential of $-70 \mathrm{mV}$ to isolate EPSCs. Drugs were dissolved in the Krebs solution and applied by superfusion.

Transfection of CCR-8 siRNA by electroporation. siRNA against CCR-8 were obtained from Bonac Corporation (Kurume, Japan) (GenBank accession number: NM_007720, mCcr8\#1 sense 5'-GCAAGAAACUGAGGAGCAU-3', anti-sense $5^{\prime}$-AUGCUCCUCAGUUUCUUGC- $3^{\prime}$, mCcr8\#2 sense $5^{\prime}$-GAGCAGUC UUUGAGGUGGA-3', anti-sense 5'-UCCACCUCAAAGACUGCUC-3', and mCcr8\#3 sense $5^{\prime}$-GAGAGAAGUUUAAGAAACA-3', anti-sense $5^{\prime}$-UGUUUCUUAAACUUCU CUC-3'). Mice were anesthetized by pentobarbital sodium ( $50 \mathrm{mg} / \mathrm{kg}$, i.p.). Mixed siRNA $(0.2 \mu \mathrm{g} / \mu \mathrm{l}, 10 \mu \mathrm{l})$ was injected i.t. using a $25-\mu \mathrm{l}$ Hamilton syringe with a 28gauge needle (Muranaka Medical Instruments co. LTD.). ${ }^{55,56}$ Scrambled siRNA (sense $5^{\prime}$-UACUAUUCGACACGCGAAG- $3^{\prime}$, anti-sense $5^{\prime}$-CUUCGCGUGUCGAAUAGUA-3'; Bonac Corporation) was used as a negative control. A volume of $5 \mu$ l was used for the i.t. injections at each points. Electric pulses (poring pulse: $75 \mathrm{~V}, 5 \mathrm{~ms}$ of length with 50 -ms interval, transfer pulse: $20 \mathrm{~V}, 50 \mathrm{~ms}$ of length with 50 -ms interval) were delivered using NEPA21 (Nepa Gene, Ichikawa, Japan). ${ }^{57,58}$ Knock-down effects were evaluated by western blotting.

Cell culture. Cortex neurons were obtained from embryonic days 14-16 ddY mice as described previously. ${ }^{59}$ Briefly, neurons were cultured at $37^{\circ} \mathrm{C}$ in a $10 \%$ $\mathrm{CO}_{2}$ incubator for 5-7 days with neurobasal medium (GIBCO, Grand Island, NY, USA) containing 2\% B27 supplement (GIBCO) and $0.5 \mathrm{mM}$ L-glutamine (GIBCO).

Immunocytochemical analysis. Primary cultured cells were fixed with $4 \%$ paraformaldehyde for $30 \mathrm{~min}$ at room temperature and permeabilized with $0.1 \%$ TritonX-100 in PBS for 5 min, followed by treating with blocking solution (Block Ace; Dainippon Pharmaceutical, Osaka, Japan) for $30 \mathrm{~min}$ at room temperature. Cells were incubated with primary antibodies: CCR-8 (1:200, Epitomics), MAP2 (1:1000, Sigma, St. Louis, MO, USA), VGLUT1 (1:1000, Synaptic Systems, Göttingen, Germany) or VGAT $\left(1: 500\right.$, Synaptic Systems) overnight at $4{ }^{\circ} \mathrm{C}$. The cells were washed in PBS and then incubated for $3 \mathrm{~h}$ at room temperature with secondary antibody (IgG-conjugated Alexa Fluor 488 or 568 or $633,1: 1000$, Molecular Probes). The cells were washed in PBS and treated with $4^{\prime}, 6$ diamidino-2-phenylindole (DAPI, $300 \mathrm{nM}$, Molecular Probes) for $10 \mathrm{~min}$ and then washed with PBS. Slides were cover-slipped with permafluor aqueous mounting medium. The sections were analyzed using a confocal laser scanning microscope (LSM510META, Carl Zeiss).

Statistical analysis. All data are presented as mean \pm S.E.M. The statistical analyses of the results were evaluated by using two-tailed Student's paired or unpaired t-test, one-way ANOVA followed by Student-Newman-Keuls test, one-way ANOVA followed by Bonferroni's test or two-way ANOVA followed by Tukey-Kramer test. $P<0.05$ was considered statistically significant.

\section{Conflict of Interest}

The authors declare no conflict of interest. 
Acknowledgements. This work was supported, in part, by a Grant-inAid from the Ministry of Education, Culture, Sports, Science and Technology of Japan (No. 22590084 to MN, No. 22590252 to YT, No.23590731 to KH No. 23390156 to Dr. Hidemasa Furue and No. 5269 to NA). And this work was also supported by fund from the Central Research Institute of Fukuoka University. We appreciate the Research Support Center, Graduate School of Medical Sciences, Kyushu University for the technical support. We also thank Dr. Hidemasa Furue (National Institute for Physiological Sciences, Japan) for helping with the electrophysiological experiments, Professor Kazuhide Inoue and Dr. Hidetoshi Tozaki-Saitoh (Kyushu University) for an experimental equipment for behavioural test.

1. Woolf CJ, Mannion RJ. Neuropathic pain: aetiology, symptoms, mechanisms, and management. Lancet 1999; 353: 1959-1964.

2. Inoue K, Tsuda M. Microglia and neuropathic pain. Glia 2009; 57: 1469-1479.

3. Inoue K, Tsuda M, Koizumi S. ATP- and adenosine-mediated signaling in the central nervous system: chronic pain and microglia: involvement of the ATP receptor P2 $\times 4$. J Pharmacol Sci 2004; 94: 112-114.

4. Scholz J, Woolf CJ. The neuropathic pain triad: neurons, immune cells and glia. Nat Neurosci 2007; 10: 1361-1368.

5. Petrenko AB, Yamakura T, Baba H, Shimoji K. The role of N-methyl-D-aspartate (NMDA) receptors in pain: a review. Anesth Analg 2003; 97: 1108-1116.

6. Zhou HY, Chen SR, Pan HL. Targeting N-methyl-D-aspartate receptors for treatment of neuropathic pain. Expert Rev Clin Pharmacol 2011; 4: 379-388.

7. Laube B, Kuhse J, Betz H. Evidence for a tetrameric structure of recombinant NMDA receptors. J Neurosci 1998; 18: 2954-2961.

8. Lu WY, Jackson MF, Bai D, Orser BA, MacDonald JF. In CA1 pyramidal neurons of the hippocampus protein kinase $C$ regulates calcium-dependent inactivation of NMDA receptors. J Neurosci 2000; 20: 4452-4461.

9. Tingley WG, Ehlers MD, Kameyama K, Doherty C, Ptak JB, Riley CT et al. Characterization of protein kinase $\mathrm{A}$ and protein kinase $\mathrm{C}$ phosphorylation of the $\mathrm{N}$-methyl-D-aspartate receptor NR1 subunit using phosphorylation site-specific antibodies. J Biol Chem 1997; 272: $5157-5166$

10. Zou X, Lin Q, Willis WD. Enhanced phosphorylation of NMDA receptor 1 subunits in spinal cord dorsal horn and spinothalamic tract neurons after intradermal injection of capsaicin in rats. J Neurosci 2000; 20: 6989-6997.

11. Milligan ED, Watkins LR. Pathological and protective roles of glia in chronic pain. Nat Rev Neurosci 2009; 10: 23-36.

12. Thacker MA, Clark AK, Marchand F, McMahon SB. Pathophysiology of peripheral neuropathic pain: immune cells and molecules. Anesth Analg 2007; 105: 838-847.

13. Calvo M, Dawes JM, Bennett DL. The role of the immune system in the generation of neuropathic pain. Lancet Neurol 2012; 11: 629-642.

14. Ren K, Dubner R. Interactions between the immune and nervous systems in pain. Nat Med 2010; 16: 1267-1276.

15. Dominguez E, Rivat C, Pommier B, Mauborgne A, Pohl M. JAK/STAT3 pathway is activated in spinal cord microglia after peripheral nerve injury and contributes to neuropathic pain development in rat. $J$ Neurochem 2008; 107: 50-60.

16. Tsuda M, Shigemoto-Mogami Y, Koizumi S, Mizokoshi A, Kohsaka S, Salter MW et al. $\mathrm{P} 2 \times 4$ receptors induced in spinal microglia gate tactile allodynia after nerve injury. Nature 2003; 424: 778-783.

17. Abbadie C, Bhangoo S, De Koninck $Y$, Malcangio M, Melik-Parsadaniantz S, White FA. Chemokines and pain mechanisms. Brain Res Rev 2009; 60: 125-134.

18. Bajetto A, Bonavia R, Barbero S, Schettini G. Characterization of chemokines and their receptors in the central nervous system: physiopathological implications. I Neurochem 2002; 82: 1311-1329.

19. Biber K, Vinet J, Boddeke HW. Neuron-microglia signaling: chemokines as versatile messengers. J Neuroimmunol 2008; 198: 69-74.

20. Coyle DE. Partial peripheral nerve injury leads to activation of astroglia and microglia which parallels the development of allodynic behavior. Glia 1998; 23: 75-83.

21. Luo Y, Laning J, Devi S, Mak J, Schall TJ, Dorf ME. Biologic activities of the murine betachemokine TCA3. J Immunol 1994; 153: 4616-4624.

22. Tiffany HL, Lautens LL, Gao JL, Pease J, Locati M, Combadiere $C$ et al. Identification of CCR8: a human monocyte and thymus receptor for the CC chemokine I-309. J Exp Med 1997; 186: 165-170.

23. Gosselin RD, Suter MR, Ji RR, Decosterd I. Glial cells and chronic pain. Neuroscientist 2010; 16: 519-531.

24. Biber K, Tsuda M, Tozaki-Saitoh H, Tsukamoto K, Toyomitsu E, Masuda T et al. Neuronal CCL21 up-regulates microglia P2 $\times 4$ expression and initiates neuropathic pain development. EMBO J 2011; 30: 1864-1873.

25. Jung H, Toth PT, White FA, Miller RJ. Monocyte chemoattractant protein-1 functions as a neuromodulator in dorsal root ganglia neurons. J Neurochem 2008; 104: 254-263.

26. Van Steenwinckel J, Reaux-Le Goazigo A, Pommier B, Mauborgne A, Dansereau MA, Kitabgi P et al. CCL2 released from neuronal synaptic vesicles in the spinal cord is a major mediator of local inflammation and pain after peripheral nerve injury. J Neurosci 2011; 31: 5865-5875.

27. Gao YJ, Ji RR. Targeting astrocyte signaling for chronic pain. Neurotherapeutics 2010; 7: 482-493.

28. Miyoshi K, Obata K, Kondo T, Okamura H, Noguchi K. Interleukin-18-mediated microglia/ astrocyte interaction in the spinal cord enhances neuropathic pain processing after nerve injury. J Neurosci 2008; 28: 12775-12787.

29. Zhuang $Z Y$, Gerner $P$, Woolf $C J$, Ji RR. ERK is sequentially activated in neurons, microglia, and astrocytes by spinal nerve ligation and contributes to mechanical allodynia in this neuropathic pain model. Pain 2005; 114: 149-159.

30. Smith JA, Das A, Ray SK, Banik NL. Role of pro-inflammatory cytokines released from microglia in neurodegenerative diseases. Brain Res Bull 2011; 87: 10-20.

31. Beggs S, Trang T, Salter MW. P2X4R + microglia drive neuropathic pain. Nat Neurosci 2012; 15: 1068-1073.

32. Kettenmann H, Hanisch UK, Noda M, Verkhratsky A. Physiology of microglia. Physiol Rev 2011; 91: 461-553.

33. Guo LH, Schluesener HJ. Lesional accumulation of P2X(4) receptor( + ) macrophages in rat CNS during experimental autoimmune encephalomyelitis. Neuroscience 2005; 134 : 199-205.

34. Verkhratsky A. Neuronismo y reticulismo: neuronal-glial circuits unify the reticular and neuronal theories of brain organization. Acta Physiol (Oxf) 2009; 195: 111-122.

35. Beattie EC, Stellwagen D, Morishita W, Bresnahan JC, Ha BK, Von Zastrow M et al. Control of synaptic strength by glial TNFalpha. Science 2002; 295: 2282-2285.

36. Fukuoka H, Kawatani M, Hisamitsu T, Takeshige C. Cutaneous hyperalgesia induced by peripheral injection of interleukin-1 beta in the rat. Brain Res 1994; 657: 133-140.

37. Hou L, Li W, Wang X. Mechanism of interleukin-1 beta-induced calcitonin gene-related peptide production from dorsal root ganglion neurons of neonatal rats. J Neurosci Res 2003; 73: 188-197.

38. Malcangio M, Bowery NG, Flower RJ, Perretti M. Effect of interleukin- 1 beta on the release of substance P from rat isolated spinal cord. Eur J Pharmacol 1996; 299: 113-118.

39. Zhang RX, Li A, Liu B, Wang L, Ren K, Zhang H et al. IL-1ra alleviates inflammatory hyperalgesia through preventing phosphorylation of NMDA receptor NR-1 subunit in rats. Pain 2008; 135: 232-239.

40. Cui JG, Holmin S, Mathiesen T, Meyerson BA, Linderoth B. Possible role of inflammatory mediators in tactile hypersensitivity in rat models of mononeuropathy. Pain 2000; 88: 239-248.

41. Fang XX, Jiang XL, Han XH, Peng YP, Qiu YH. Neuroprotection of interleukin-6 against NMDA-induced neurotoxicity is mediated by JAK/STAT3, MAPK/ERK, and PI3K/AKT signaling pathways. Cell Mol Neurobiol 2012; 33: 241-251.

42. Ringheim GE, Burgher KL, Heroux JA. Interleukin-6 mRNA expression by cortical neurons in culture: evidence for neuronal sources of interleukin-6 production in the brain. J Neuroimmunol 1995; 63: 113-123.

43. Liu XJ, Gingrich JR, Vargas-Caballero M, Dong YN, Sengar A, Beggs S et al. Treatment of inflammatory and neuropathic pain by uncoupling Src from the NMDA receptor complex. Nat Med 2008; 14: 1325-1332.

44. Ultenius $\mathrm{C}$, Linderoth B, Meyerson BA, Wallin J. Spinal NMDA receptor phosphorylation correlates with the presence of neuropathic signs following peripheral nerve injury in the rat. Neurosci Lett 2006; 399: 85-90.

45. Gao X, Kim HK, Chung JM, Chung K. Enhancement of NMDA receptor phosphorylation of the spinal dorsal horn and nucleus gracilis neurons in neuropathic rats. Pain 2005; 116 : $62-72$.

46. Abe T, Matsumura S, Katano T, Mabuchi T, Takagi K, Xu L et al. Fyn kinase-mediated phosphorylation of NMDA receptor NR2B subunit at Tyr1472 is essential for maintenance of neuropathic pain. Eur J Neurosci 2005; 22: 1445-1454.

47. Guo W, Zou S, Guan Y, Ikeda T, Tal M, Dubner R et al. Tyrosine phosphorylation of the NR2B subunit of the NMDA receptor in the spinal cord during the development and maintenance of inflammatory hyperalgesia. J Neurosci 2002; 22: 6208-6217.

48. Guo W, Wang H, Watanabe M, Shimizu K, Zou S, LaGraize SC et al. Glial-cytokineneuronal interactions underlying the mechanisms of persistent pain. J Neurosci 2007; 27: 6006-6018.

49. Seltzer Z, Dubner R, Shir Y. A novel behavioral model of neuropathic pain disorders produced in rats by partial sciatic nerve injury. Pain 1990; 43: 205-218.

50. Honda K, Koga K, Moriyama T, Koguchi M, Takano Y, Kamiya HO. Intrathecal alpha2 adrenoceptor agonist clonidine inhibits mechanical transmission in mouse spinal cord via activation of muscarinic M1 receptors. Neurosci Lett 2002; 322: 161-164.

51. Hylden JL, Wilcox GL. Intrathecal morphine in mice: a new technique. Eur J Pharmacol 1980; 67: 313-316.

52. Gao YJ, Zhang L, Samad OA, Suter MR, Yasuhiko K, Xu ZZ et al. JNK-induced MCP-1 production in spinal cord astrocytes contributes to central sensitization and neuropathic pain. J Neurosci 2009; 29: 4096-4108.

53. Yang K, Li Y, Kumamoto E, Furue H, Yoshimura M. Voltage-clamp recordings of postsynaptic currents in substantia gelatinosa neurons in vitro and its applications to assess synaptic transmission. Brain Res Brain Res Protoc 2001; 7: 235-240.

54. Yoshimura M, Nishi S. Blind patch-clamp recordings from substantia gelatinosa neurons in adult rat spinal cord slices: pharmacological properties of synaptic currents. Neuroscience 1993; 53: 519-526. 
55. Morita K, Kitayama T, Morioka N, Dohi T. Glycinergic mediation of tactile allodynia induced by platelet-activating factor (PAF) through glutamate-NO-cyclic GMP signalling in spinal cord in mice. Pain 2008; 138: 525-536.

56. Morita K, Motoyama N, Kitayama T, Morioka N, Kifune K, Dohi T. Spinal antiallodynia action of glycine transporter inhibitors in neuropathic pain models in mice. J Pharmacol Exp Ther 2008; 326: 633-645.

57. Choijookhuu N, Sato Y, Nishino T, Endo D, Hishikawa Y, Koji T. Estrogendependent regulation of sodium/hydrogen exchanger-3 (NHE3) expression via estrogen receptor beta in proximal colon of pregnant mice. Histochem Cell Biol 2012 137: 575-587.

58. Yamano T, Iguchi H, Fukuzawa $H$. Rapid transformation of Chlamydomonas reinhardtii without cell-wall removal. J Biosci Bioeng 2012; 115: 691-694.
59. Noda M, Kariura Y, Pannasch U, Nishikawa K, Wang L, Seike T et al. Neuroprotective role of bradykinin because of the attenuation of pro-inflammatory cytokine release from activated microglia. J Neurochem 2007; 101: 397-410.

(c) (-) Cell Death and Disease is an open-access journal published by Nature Publishing Group. This work is licensed under a Creative Commons Attribution-NonCommercialShareAlike 3.0 Unported License. To view a copy of this license, visit http://creativecommons.org/licenses/by-nc-sa/3.0/

Supplementary Information accompanies this paper on Cell Death and Disease website (http://www.nature.com/cddis) 